\title{
Helicobacter pylori treatment: antibiotics or probiotics
}

\author{
Kamila Goderska $^{1}$ (D) Sonia Agudo Pena ${ }^{1} \cdot$ Teresa Alarcon $^{2}$
}

Received: 31 March 2017 /Revised: 14 September 2017 / Accepted: 16 September 2017 / Published online: 26 October 2017

(C) The Author(s) 2017. This article is an open access publication

\begin{abstract}
Treatment of Helicobacter pylori infection is important for the management of gastrointestinal disorders such as peptic ulcer and gastric cancer. Due to the increase in the prevalence of $H$. pylori resistance to antibiotics, triple therapy with clarithromycin is no longer the best treatment for H. pylori, especially in some areas where the local resistance to this antibiotic is higher than $20 \%$. Alternative treatments have been proposed for the eradication of $H$. pylori. Some of them including novel antibiotics or classical ones in different combinations; these treatments are being used in the regular clinical practice as novel and more effective treatments. Others therapies are using probiotics associated to antibiotics to treat this infection.

The present article is a revision of $H$. pylori eradication treatment, focusing on emerging approaches to avoid the treatment failure, using new therapies with antimicrobials or with probiotics.
\end{abstract}

Keywords Helicobacter $\cdot$ Antibiotics $\cdot$ Probiotics $\cdot$ Intestinal microbiology $\cdot$ Antimicrobials

Kamila Goderska

kamila.goderska@up.poznan.pl

1 Faculty of Food Science and Nutrition, Institute of Food Technology of Plant Origin, Department of Fermentation and Biosynthesis, Poznan University of Life Sciences, Wojska Polskiego 31, 60-624 Poznan, Poland

2 Department of Microbiology, Hospital Universitario de La Princesa, 28006 Madrid, Spain

\section{Introduction}

Helicobacter pylori is a common bacteria infecting about half of world's population, with higher prevalence in developing countries, where $H$. pylori could infect up to $80 \%$ of the population (Moayyedi and Hunt 2004), than in developed ones.

H. pylori is associated with the development of gastrointestinal disorders as chronic gastritis, peptic ulcer, and gastric adenocarcinoma (Kuipers 1997). H. pylori is also involved in the development of other extra-gastric disorders such as mucosa-associated lymphoid tissue lymphoma (MALT), idiopathic thrombocytopenic purpura, vitamin $\mathrm{B}_{12}$ deficiency, and iron deficiency (Kuipers 1997). Eradication of H. pylori could help in the management of these H. pylori-associated disorders.

For the last two decades, the recommended treatment for H. pylori eradication is the standard triple therapy (Papastergiou et al. 2014a, b), using a proton pump inhibitor or ranitidine bismuth citrate, combined with clarithromycin and amoxicillin or metronidazole.

During the 90's, due to the fact that these treatments reached high eradication rates [more than $90 \%$ ] together with the safety profile, these triple therapies had a very high acceptance among clinicians (Malfertheiner et al. 2007). The efficacy of these triple regimens has decreased lately to rates lower than $70 \%$, due to $H$. pylori resistance to key antibiotics, mainly clarithromycin, but also metronidazole and levofloxacin (Agudo et al. 2010a, b; De Francesco et al. 2009).

These low rates of successful treatment are not acceptable under the Maastricht consensus which points out that rates consistently below $80 \%$ by intention-to-treat are not acceptable for treating H. pylori (Graham et al. 2007). Information about local resistant to antibiotics should be taken into account before establishing a treatment plan for the patient to avoid repeated treatments. Several expositions to antibiotic 
treatments could result in more side effects and a decrease in the percentage of antibiotic resistance.

For this reason, this review is an overview of $H$. pylori eradication focused on second-line therapies that are used such as sequential therapy and quadruple therapy. However, due to the increase of the antibiotic resistance, some studies have started to focus on probiotics, as a therapeutic approach. Probiotics are defined as living microbial species that can include anti-inflammatory and anti-oxidative mechanisms that may improve bowel microecology and general health (Lu et al. 2016). Probiotics are live microorganisms, which when administered in adequate amounts confer a health benefit on the host. The most used probiotic bacteria are Lactobacillus and Bifidobacterium (Ruggiero 2014). Probiotics could improve $H$. pylori eradication and reduce side effects during therapy (Kim et al. 2008). A part of this revision will be focused on using of probiotics against $H$. pylori.

\section{H. pylori resistance to antibiotics}

\section{Classical treatment}

During the 90s, the standard triple therapy was the gold standard in the treatment of $H$. pylori infections. The standard triple therapies are based on a proton pump inhibitor, clarithromycin, and amoxicillin or metronidazole. The increase in the prevalence of resistance to these antibiotics, especially to the key antibiotic, clarithromycin, has decreased the efficacy of standard regimens (Malfertheiner et al. 2002).

In a recent systematic review, the global incidence of primary $H$. pylori resistance to clarithromycin has been reported to be as high as $17.2 \%$, showing an increase worldwide (Kuipers 1997). The prevalence of $H$. pylori resistance to clarithromycin varies among different countries, such as 10.6 to $25 \%$ in North America, $16 \%$ in Japan, and 1.7 to 23.4\% in Europe (Elitsur et al. 2006; Horiki et al. 2012; Koletzko et al. 2006). This disparity in resistance rates seems to be correlated to the national level of macrolide consumption and different policies for antibiotic consumption in different countries (Agudo et al. 2010a, b), for example, 49\% of clarithromycin resistance has been reported in some Spanish areas, but only $1 \%$ in the Netherlands, reflecting a stricter Northern European policy for antibiotic use than in Southern European countries (Seck et al. 2013). New macrolides were marketed in Europe at the beginning of the 90's; patients were exposed to macrolides in order to treat respiratory infections with antibiotics of this group. Additional aspects such as geographic features, virulence factors of $H$. pylori strains, or some host aspects [age, place of birth] could contribute to the significant variation in the prevalence of antibiotic resistance (Van Doorn et al. 2000).

Metronidazole is a key component included in the triple therapies (Malfertheiner et al. 2002) which is associated to a high level of resistance. The prevalence of metronidazole resistance has been estimated to be from 17 to $44 \%$ for Europe and America, respectively (Ogata et al. 2013; De Francesco et al. 2010). The highest level of resistance to this antibiotic in Europe has been reported in Western Europe, where 20 to $45 \%$ of the $H$. pylori isolates are metronidazole-resistant (Lopez-Brea et al. 2001). The percentage of metronidazole resistance in developing countries has been reported from 50 to $100 \%$, instead of being up to $90 \%$ in Africa (Falsafi et al. 2004). The resistance to metronidazole is so high in developing countries because this antibiotic is widely used to treat parasitic and/or gynecological infections in female patients (John et al. 2006). Also, there are some studies describing that metronidazole resistance being linked to the virulence strain factors, the strains without $\operatorname{cagA}$ gene being more resistant (Taneike et al. 2009). The lower rates related to metronidazole resistance have been reported in Japan, around 10\% (De Francesco et al. 2010).

Based on these publications, standard triple therapies may not be recommended anymore for empiric use. Due to the high level of resistance to the two key antibiotics of standard triple therapies, clarithromycin and metronidazole, and the different patterns of resistance in different populations, standard triple therapies should be adapted to the local resistance pattern, and when possible, treatment should be based on susceptibility data obtained by testing the strain after culture.

Alternative strategies are being implemented in clinical practice to treat $H$. pylori-resistant strains. This included development and use of novel and more effective treatments and use of probiotics to improve the eradication regimens and decrease the antibiotic side effects.

During this revision, new treatment against $H$. pylori and probiotics therapies will be discussed.

\section{Bismuth quadruple therapy}

This therapy contains two antibiotics, tetracycline and metronidazole, plus bismuth and PPI for 14 days (Harb et al. 2015). This therapy is preferred as a first-line treatment option for areas with a high incidence of clarithromycin resistance and also as second-line therapy when first treatment with the classical triple therapy against $H$. pylori was failed (Papastergiou et al. 2014a, b). This therapy works totally independent of clarithromycin, the most problematic antibiotic in terms of resistance. Related to metronidazole, the use of high doses and prolonged treatment duration allows minimizing the impact on metronidazole-resistant strains, providing high eradication rates even in areas with high level of resistance to this antibiotic (Lee et al. 2014).

The potential toxicity of bismuth as well as the nonavailability of bismuth salts or tetracycline in some countries is the main impediment related to this therapy. In 
some studies, tetracycline was substituted by amoxicillin (Perri et al. 2002).

Nine randomized controlled trials were analyzed in a metaanalysis (Luther et al. 2010), comparing bismuth quadruple therapy and clarithromycin triple therapy; they found that bismuth quadruple therapy achieved eradication in $78.3 \%$ of patients, whereas clarithromycin triple therapy achieved an eradication rate of $77 \%$. The conclusion was that quadruple and triple therapies have similar eradication rates as primary therapy for $H$. pylori infection. On the other hand, the efficacy of this therapy has been confirmed as second-line treatment in a meta-analysis based on 30 studies showing $77 \%$ of eradication after failure of standard triple therapy (Gisbert 2012).

\section{Sequential therapy}

Sequential therapy uses the same antibiotics as standard triple therapy, but they are given them sequentially: 5 days with a PPI plus amoxicillin, followed by 5 days of PPI plus clarithromycin and amoxicillin (Kuipers 1997).

Amoxicillin is administrated first, due to the fact that amoxicillin disrupts the bacterial cell walls to prevent the development of efflux channels transferring the rest of the antibiotics out of bacteria (Webber and Piddock 2003). There were some studies published, the majority of them in Italy, where the result of sequential therapy was superior to normal standard triple therapy. More recent data from studies developed in South America and Asia shows eradication rates lower than 80\% (Kuipers 1997).

In a recent meta-analysis, 36 randomized clinical trials were reviewed. The eradication rate was $84.1 \%$ for the sequential therapy in comparison with $75.1 \%$ for the standard triple therapy. Sequential therapy seems to be more effective against patients with the single clarithromycin-resistant strain; eradication rates were $80.9 \%$ for sequential therapy and $40.7 \%$ for standard triple therapy (Feng et al. 2015).

\section{Non-bismuth quadruple therapy}

It is another valid therapy in countries with high incidence to clarithromycin resistance. This therapy contains PPI [but without bismuth], clarithromycin, amoxicillin, and metronidazole for 10 days. The main disadvantage of this treatment is the large number of pills in comparison with other therapies (Papastergiou et al. 2014a, b).

In a meta-analysis carried out in 2012 including randomized controlled studies comparing non-bismuth quadruple therapy and the standard triple therapy, the eradication rate was 90 vs. $78 \%$, respectively. Clarithromycin resistance may reduce the efficacy of non-bismuth quadruple therapy, although the decrease in eradication rates seems to be far lower than in standard triple therapy (Gisbert and Cavet 2012).

\section{Hybrid therapy}

This therapy is based on 7 days of therapy with PPI and amoxicillin, followed by 7 days quadruple therapy with a PPI, amoxicillin, clarithromycin, and metronidazole. There are not many data in the literature, comparing this therapy with others, the standard or sequential therapies, but the results do not indicate that hybrid therapy will be superior to sequential therapy (Papastergiou et al. 2014a, b).

There is a review where five studies were identified comparing hybrid therapy and sequential therapy, and three comparing hybrid therapy and concomitant therapy. The five randomized controlled trials revealed no significant differences between hybrid therapy and sequential therapy, and the three randomized control trials showed no significant differences between hybrid therapy and concomitant therapy (He et al. 2015).

\section{Levofloxacin-based therapies}

Due to the increase of clarithromycin resistance, levofloxacin, a broad spectrum quinolone, is used for the $H$. pylori eradication in order to substitute clarithromycin in triple or sequential regimens. The eradication rate of therapies containing levofloxacin could be more than $90 \%$, especially in areas where the local resistance to levofloxacin is low [less than 10\%]. As for clarithromycin and metronidazole, an increase of levofloxacin resistance is being found, due to the fact that quinolones are often used for the treatment of urinary infections. The resistance to quinolones is around 20\% in Europe, $15 \%$ in America, and $10 \%$ in Asia (Liang et al. 2014).

Due to the rapid development of secondary quinolone resistance, first-line use of levofloxacin is generally discouraged, and the drug is reserved for use in second-line regimens after failure of clarithromycin and/or metronidazole-based regimens (Gisbert et al. 2015).

\section{Probiotic's microorganism}

Probiotics are defined as living microorganisms that, when administered in adequate amounts, can improve microbial balance in the intestine and exert positive health effects on the host (FAO/WHO 2002), including beneficial effects on the prevention of intestinal infections, cardiovascular disease, cancer, and anti-allergic effects (Pianoa et al. 2006).

Probiotics can be microorganisms from the bacteria or yeasts group. However, most of probiotics are bacteria, among them lactic acid bacteria, typically associated with the human gastrointestinal tract, which are the most widely used (Rodes et al. 2013b). They include Gram (+) cocci and rods Lactobacillus and Bifidobacterium, which are the two most common species used as probiotics and are extensively investigated for their beneficial effects on the host, including promotion of gut maturation and integrity, antagonism against 
pathogens, and modulation of the immune system and tumorpromoting agents. A common feature of these bacteria is the ability of anaerobic digestion of saccharides and production of lactic acid. These microorganisms are characterized by a resistance to low $\mathrm{pH}$ and tolerance to a wide range of temperatures. The natural ecosystem of the lactic acid bacteria is the digestive tract, mucous membrane of the mouth, and genital tract of humans and animals (Rodes et al. 2013a).

Due to fact that $H$. pylori has been regarded as a difficultto-treat infection mainly because of acquired resistance to commonly used antibiotics, there is a growing interest in using probiotics in conjunction with antibiotic regimens to eradicate H. pylori. Probiotics have been proven to be useful in the treatment of several intestinal diseases such as diarrhea, in addition to the benefits of probiotic bacteria in the intestines; some beneficial effects on the stomach have been reported. Among them, the anti-Helicobacter pylori activity has been studied (Aiba et al. 2015).

The benefits of probiotic therapy in H. pylori case are increased eradication and improved tolerability by preventing the occurrence of treatment and related side effects.

Also, probiotics may help to improve the H. pylori-related diseases. The clinical outcome of $H$. pylori infection is determined by several factors, including the type of $H$. pylori strain, the extent of inflammation, and the density of $H$. pylori colonization. It has been reported that the risk of development of peptic ulcer disease and gastric cancer increases with an increasing level of infection. Therefore, permanent or long-term suppression of $H$. pylori could decrease the risk of developing H. pylori-related diseases (Yang et al. 2014).

Several studies have been conducted to show the favorable effect of different probiotics against $H$. pylori and have clarified the mechanism of action of probiotics against $H$. pylori, including strength of mucosal barrier, competition for adhesion, and immunomodulatory mechanisms (Papastergiou et al. 2014a, b).

\section{Mechanism of action}

Nonimmunological mechanism The first line of defense against pathogenic bacteria is acidity of the stomach and the gastric mucosa barrier. It was suggested that, by taking probiotics, this first line of defense could be stronger due to the production of antimicrobial substances competing with H. pylori for adhesion receptors, stimulating mucin production and stabilizing the gut mucosal barrier.

Antimicrobial substances Probiotics may inhibit $H$. pylori growth by secreting short chain fatty acids and antibacterial substances. Short chain fatty acids such as acetic, propionic, and lactic acids are produced during the carbohydrates metabolism by probiotics and as consequence, a pH reduction are found. In 1989, Bhatia et al. (1989) were the first group to observe an antagonistic effect of a Lactobacillus strain against $H$. pylori related to short chain fatty acids. Also, antimicrobial activity could be due to the inhibition of urease activity of $H$. pylori as has been shown in other publications (Sgouras et al. 2004).

Certain Lactobacillus species synthesize antimicrobial compounds related to the bacteriocin classes. Bacteriocins are proteinaceous toxins with potential anti- $H$. pylori activity. They are small and dialysable peptidic structures with antimicrobial activities. Antimicrobial activity of the bacteriocins varied among the H. pylori strains and also the type of bacteriocins produced by Lactobacillus sp. Some bacteriocins have shown a stronger antibacterial activity against $H$. pylori strains than others, although both were produced by Lactobacillus spp. (Kim et al. 2003).

Competition for adhesion There are several possible mechanisms by which probiotic bacteria can inhibit the adhesion of $H$. pylori. The adhesion of $H$. pylori to epithelial cells is important in determining the outcome in $\mathrm{H}$. pylori-associated diseases; the ability of the bacteria to establish physical contact with the gastric epithelium is affected by the influence of the epithelial mucosa, receptors associated with the adhesion of $H$. pylori to epithelium, and immune cells (Zhang et al. 2014).

There are several possible mechanisms by which probiotic bacteria can inhibit the adhesion of $H$. pylori, mainly lactic acid and bacteriocins (Lesbros-Pantoflickova et al. 2007).

Mucosal barrier Mucosal surfaces have protective strategies to defend against noxious substances and pathogens found within the intestinal lumen. Some strategies, such as mucins, large complex glycoproteins that protect intestinal mucosal surfaces from microbial pathogens by limiting access of environmental matter to their epithelial cells (Mack et al. 2003). Several mucins have been identified. H. pylori is known to suppress MUCI and MUC5 gene expression in a human gastric cell line (Hanisch et al. 2014). It has been shown that in vitro studies with probiotics such as $L$. plantarum and L. rhamnosus increase the expression of MUC2 and MUC3 genes and therefore extracellular secretion of mucin by colon cell cultures can inhibit the adherence of pathogenic bacteria. This ability of these strains restores the mucosal permeability of gastric mucosa and inhibits the adherence of pathogenic bacteria such as $H$. pylori.

Immunologic mechanisms The inflammatory response to gastric $H$. pylori infection is characterized by the release of various inflammatory mediators such as chemokines and cytokines. Probiotics could modify the immunologic response by the modulation of anti-inflammatory cytokines secretion, which would result in a reduction of gastric activity and inflammation (Wiese et al. 2012). 
Clinical trials with probiotics against H. pylori

Reviewed papers related to probiotics and H. pylori have been search for in PUBMED for the last 10 years (from January 2004 to July 2017), by introducing keywords such as "review," "probiotics," "Helicobacter," and "treatment"; 159 articles were obtained, but only 34 of them were related to probiotics and H. pylori. Based on the data found in these papers, probiotics cannot be considered as an alternative to anti-H. pylori treatment, but their use in association with standard anti-H. pylori treatment could improve the treatment of $H$. pylori by increasing eradication rates as well as decreasing the adverse effects of current medication therapy. This was the conclusion of the four meta-analyses related to $H$. pylori treatment and probiotics published between 2016 and 2017 (Lü et al. 2016, McFarland et al. 2016, Feng et al. 2017, Wang et al. 2017).

There is a scientific report published by Nature in 2016 that described the meta-analysis included eligible randomized controlled trials with the aim of determining whether probiotic supplementation can improve H. pylori eradication and reduce side effects during therapy (Dang et al. 2014). Authors investigated the effect of combining probiotics, with or without a placebo, without standard therapy. Compared to the placebo group, the probiotics group was eradication of $H$. pylori infection in intent-to-treat analysis and per protocol analysis, respectively. Probiotics with triple therapy plus a 14-day course of treatment did not improve the eradication of H. pylori infection compared to the placebo. However, probiotics did improve the adverse effects of diarrhea and nausea. These pooled dates suggest that the use of probiotics plus standard therapy does not improve the eradication rate of H. pylori infection compared to the placebo. Some metaanalysis has reported that probiotics supplementation can improve the eradication rate of $H$. pylori compared to the therapy alone. Maybe it is widely accepted that probiotics can improve H. pylori eradication and reduce side effects during standard therapy, but some species from a group of probiotic bacteria can help the pharmacotherapy. Consumption of fermented products in diet (f.ex. $250 \mathrm{~g}$ of milk fermented product) can improve gastrointestinal tract with good microorganism in the gastrointestinal tract. These data suggested that the use of probiotics plus standard therapy does not improve the eradication rate of $H$. pylori infection compared to the placebo. A placebo is a simulated or otherwise medically ineffectual treatment for a disease or other medical condition that intends to deceive the recipient. It is well known that physiological phenomena are closely associated with gastric diseases. In addition, the placebo effect generates alternation in the levels of systematic and enteric hormones and subject-expectancy effects (Dong et al. 2012; Lesbros-Pantoflickova et al. 2007; Ruggiero 2014; Vítor and Vale 2011; Patel et al. 2014; Sachdeva and Nagpal 2009; Zou et al. 2009; Franceschi et al. 2007; Lionetti et al. 2010; Zhengn et al. 2013; Patel et al. 2014; Pacifico et al. 2014; Sabbi 2011; Tong et al. 2007; Wilhelm et al. 2011; Gotteland et al. 2006). Metaanalysis shows that eradication rate of $H$. pylori infections in the probiotics group vs. the placebo and non-placebo groups in ITT analysis and estimates the OR with $95 \%$ covalence interval and weight percentage.

\section{Conclusion}

Triple regimens containing two antimicrobial agents have been the standard therapies against $H$. pylori infection for more than 15 years. However, the increase in the prevalence of macrolide resistance, mainly clarithromycin, has decreased the efficacy of these therapies to unacceptably low levels in most parts of the world, resulting in the necessity of studying other possible therapies in order to eradicate the pathogen.

These therapies are the bismuth quadruple, sequential, and hybrid therapies. Due to the rapid development of quinolone resistance, levofloxacin-based regimens should be reserved as a second-line treatment option.

Related to probiotics, probiotics could not be recommended to be used as a single agent for eradication therapy. However, their use associated to standard treatment as an adjunct will improve the eradiation rates and decrease treatmentrelated side effects.

Funding This study was not funded, this is a review article.

\section{Compliance with ethical standards}

Ethical approval This article does not contain any studies with human participants or animals performed by any of the authors.

Conflict of interest The authors declare that they have no competing interests.

Open Access This article is distributed under the terms of the Creative Commons Attribution 4.0 International License (http:// creativecommons.org/licenses/by/4.0/), which permits unrestricted use, distribution, and reproduction in any medium, provided you give appropriate credit to the original author(s) and the source, provide a link to the Creative Commons license, and indicate if changes were made.

\section{References}

Agudo S, Alarcon T, Urruzuno P, Martinez T, Lopez-Brea M (2010a) Detection of Helicobacter pylori and clarithromycin resistance in gastric biopsies of pediatric patients by using a commercially available real-time polymerase chain reaction after NucliSens semiautomated DNA extraction. Diagn Microbiol Infect Dis 67(3): 213-219

Agudo S, Perez-Perez G, Alarcón T, López-Brea M (2010b) High prevalence of clarithromycin-resistant Helicobacter pylori strains and 
risk factors associated with resistance in Madrid, Spain. J Clin Microbiol 48(10):3703-3707

Aiba Y, Nakano Y, Koga Y, Takahashi K, Komatsu Y (2015) A highly acid-resistant novel strain of Lactobacillus johnsonii No. 1088 has antibacterial activity, including that against Helicobacter pylori, and inhibits gastrin-mediated acid production in mice. Microbiology 4(3):465-474

Bhatia SJ, Kochar N, Abraham P, Nair NG, Mehta AP (1989) Lactobacillus acidophilus inhibits growth of Campylobacter pylori in vitro. J Clin Microbiol 27:2328-2330

Dang Y, Reinhardt JD, Zhou X, Zhang G (2014) The effect of probiotic supplementation on Helicobacter pylori eradication therapy: a metaanalysis. PLoS One 9(11):1-15

De Francesco V, Zullo A, Lerardi E, Vaira D (2009) Minimal inhibitory concentration (MIC) values and different point mutations in the $23 \mathrm{~S}$ rRNA gene for clarithromycin resistance in Helicobacter pylori. Dig Liver Dis 41:610-611

De Francesco V, Giorgio F, Hassan C, Manes G, Vannella L, Panella C, Ierardi E, Zullo A (2010) Worldwide H. pylori antibiotic resistance: a systematic review. J Gastrointestin Liver Dis 19:409-414

Dong H, Rowland I, Yaqob P (2012) Comparative effects of six probiotic strains on immune function in vitro. Br J Nutr 108:459-470

Elitsur Y, Lawrence Z, Rüssmann H, Koletzko S (2006) Primary clarithromycin resistance to Helicobacter pylori and therapy failure in children: the experience in West Virginia. J Pediatr Gastroenterol Nutr 42:327-328

Falsafi T, Mobasheri F, Nariman F, Najafi M (2004) Susceptibilities to different antibiotics of Helicobacter pylori strains isolated from patients at the pediatric medical center of Tehran, Iran. J Clin Microbiol 42:387-389

FAO/WHO (2002) Guidelines for the evaluation of probiotics in food. Food and Agriculture Organization of the United Nations/World Health Organization, London

Feng L, Wen MY, Zhu YJ, Men RT, Yang L (2015) Sequential therapy or standard triple therapy for Helicobacter pylori infection: an updated systematic review. Am J Ther 23(3):880-893

Feng JR, Wang F, Qiu X, McFarland LV, Chen PF, Zhou R, Liu J, Zhao Q, Li J (2017) Efficacy and safety of probiotic-supplemented triple therapy for eradication of Helicobacter pylori in children: a systematic review and network meta-analysis. Eur J Clin Pharmacol. https://doi.org/10.1007/s00228-017-2291-6

Franceschi F, Cazzato A, Nista EC, Scarpellini E, Roccarina D, Gigante G, Gasbarrini G, Gasbarrini A (2007) Role of probiotics in patients with Helicobacter pylori infection. Helicobacter 12:59-63

Gisbert JP (2012) Rescue therapy for Helicobacter pylori infection. Gastroenterol Res Pract. https://doi.org/10.1155/2012/974594

Gisbert J, Cavet X (2012) Update on non-bismuth quadruple (concomitant) therapy for eradication of Helicobacter pylori. Clin Exp Gastroenterol 5:23-34

Gisbert JP, Romano M, Gravina AG, Solís-Muñoz P, Bermejo F, MolinaInfante J, Castro-Fernández M, Ortuño J, Lucendo AJ, Herranz M, Modolell I, Del Castillo F, Gómez J, Barrio J, Velayos B, Gómez B, Domínguez JL, Miranda A, Martorano M, Algaba A, Pabón M, Angueira T, Fernández-Salazar L, Federico A, Marín AC, McNicholl AG (2015) Helicobacter pylori second-line rescue therapy with levofloxacin- and bismuth-containing quadruple therapy, after failure of standard triple or non-bismuth quadruple treatments. Aliment Pharmacol Ther 41(8):768-775

Gotteland M, Brunser O, Cruchet S (2006) Systematic review: are probiotics useful in controlling gastric colonization by Helicobacter pylori? Aliment Pharmacol Ther 23(8):1077-1086

Graham DY, Lu H, Yamaoka Y (2007) A report card to grade Helicobacter pylori therapy. Helicobacter 12:275-278

Hanisch FG, Bonar D, Schloerer N, Schroten H (2014) Human trefoil factor 2 is a lectin that binds $\alpha$-GlcNAc-capped mucin glycans with antibiotic activity against Helicobacter pylori. J Biol Chem 289(40): 27363-27375

Harb A, Zeinab D, Sarkis S, Chaar H, Sharara A (2015) Efficacy of reduced-dose regimen of a capsule containing bismuth subcitrate, metronidazole, and tetracycline given with amoxicillin and esomeprazole in the treatment of Helicobacter pylori infection. United European Gastroenterol J 3(1):95-96

He L, Deng T, Luo H (2015) Meta-analysis of sequential, concomitant and hybrid therapy for Helicobacter pylori eradication. Intern Med 54(7):703-710

Horiki N, Omata F, Uemura M, Suzuki S, Ishii N, Iizuka Y, Fukuda K, Fujita Y, Katsurahara M, Ito T, Cesar GE, Imoto I, Takei Y (2012) Risk for local recurrence of early gastric cancer treated with piecemeal endoscopic mucosal resection during a 10-year follow-up period. Surg Endosc 26(1):72-78

John M, Al-Mekhaizeem K, Neil L, Dhar R, Dhar PM, Al-Ali M (2006) High prevalence and level of resistance to metronidazole, but lack of resistance to other antimicrobials in Helicobacter pylori, isolated from a multiracial population in Kuwait. Aliment Pharmacol Ther 24:1359-1366

Kim TS, Hur JW, Yu MA, Cheigh CI, Kim KN, Hwang JK, Pyun YR (2003) Antagonism of Helicobacter pylori by bacteriocins of lactic acid bacteria. J Food Prot 66(1):3-12

Kim MN, Lee SH, Park YS, Hwang JH, Kim JW, Jeong SH, Lee DH, Kim JS, Jung HC, Song IS (2008) The effects of probiotics on PPItriple therapy for Helicobacter pylori eradication. Helicobacter 13(4):261-268

Koletzko S, Richy F, Bontems P, Crone J, Kalach N, Monteiro ML, Gottrand F, Celinska-Cedro D, Roma-Giannikou E, Orderda G, Kolacek S, Urruzuno P, Martínez-Go'mez MJ, Casswall T, Ashorn M, Bodanszky H, Megraud F (2006) Prospective multicentre study on antibiotic resistance of Helicobacter pylori strains obtained from children living in Europe. Gut 55:1711-1716

Kuipers EJ (1997) Helicobacter pylori and the risk and management of associated diseases: gastritis, ulcer disease, atrophic gastritis and gastric cancer. Aliment Pharmacol Ther 11(1):71-88

Lee ST, Lee DH, Lim JH, Kim N, Park YS, Shin CM, Jo HJ, Song IS (2014) Efficacy of 7-day and 14-day bismuth-containing quadruple therapy and 7-day and 14-day moxifloxacin-based triple therapy as second-line eradication for Helicobacter pylori infection. Gut Liver 9(4):478-485

Lesbros-Pantoflickova D, Corthésy-Theulaz I, Blum AL (2007) Helicobacter pylori and probiotics. J Nutr 137:812-818

Liang CM, Cheng JW, Kuo CM, Chang KC, Wu KL, Tai WC, Chiu KW, Chiou SS, Lin MT, Hu TH, Chuah SK (2014) Levofloxacincontaining second-line anti-Helicobacter pylori eradication in Taiwanese real-world practice. Biom J 37(5):326-330

Lionetti E, Indrio F, Pavone L, Borrelli G, Cavallo L, Francavilla R (2010) Role of probiotics in pediatric patients with Helicobacter pylori infection: a comprehensive review of the literature. Helicobacter 15(2):79-87

Lopez-Brea M, Martinez MJ, Domingo D, Alarcon T (2001) A 9 year study of clarithromycin and metronidazole resistance in Helicobacter pylori from Spanish children. J Antimicrob Chemother 48:295-297

Lu C, Sang J, He H, Wan X, Lin Y, Li L, Li Y, Yu C (2016) Probiotic supplementation does not improve eradication rate of Helicobacter pylori infection compared to placebo based on standard therapy: a meta-analysis. Nat Sci Rep 6:23522

Lü M, Yu S, Deng J, Yan Q, Yang C, Xia G, Zhou X (2016) Efficacy of probiotic supplementation therapy for Helicobacter pylori eradication: a meta-analysis of randomized controlled trials. PLoS One 11(10): $\mathrm{e} 0163743$

Luther J, Higgins PD, Schoenfeld PS, Moayyedi P, Vakil N, Chey WD (2010) Empiric quadruple vs. triple therapy for primary treatment of 
Helicobacter pylori infection: systematic review and meta-analysis of efficacy and tolerability. Am J Gastroenterol 105:65-73

Mack D, Ahrne S, Hyde L, Wei S, Hollingsworth MA (2003) Extracellular MUC3 mucin secretion follows adherence of Lactobacillus strains to intestinal epithelial cells in vitro. Gut 52: 827-833

Malfertheiner P, Mégraud F, O'Morain C, Hungin AP, Jones R, Axon A, Graham DY, Tytgat G (2002) Current concepts in the management of Helicobacter pylori infection - the Maastricht 2-2000 Consensus Report. Aliment Pharmacol Ther 16:167-180

Malfertheiner P, Megraud F, O’Morain C, Bazzoli F, El-Omar E, Graham D, Hunt R, Rokkas T, Vakil N, Kuipers EJ (2007) Current concepts in the management of Helicobacter pylori infection: the Maastricht III Consensus Report. Gut 56:772-781

McFarland LV, Huang Y, Wang L, Malfertheiner P (2016) Systematic review and meta-analysis: multi-strain probiotics as adjunct therapy for Helicobacter pylori eradication and prevention of adverse events. United European Gastroenterol J 4(4):546-561

Moayyedi P, Hunt RH (2004) Helicobacter pylori public health implications. Helicobacter 9(1):67-72

Ogata SK, Godoy AP, da Silva Patricio FR, Kawakami E (2013) High Helicobacter pylori resistance to metronidazole and clarithromycin in Brazilian children and adolescents. J Pediatr Gastroenterol Nutr 56(6):645-648

Pacifico L, Osborn J, Bonci E, Romaggioli S, Baldini R, Chiesa C (2014) Probiotics for the treatment of Helicobacter pylori infection in children. World J Gastroenterol 20(3):673-683

Papastergiou V, Georgopoulos S, Karatapanis S (2014a) Treatment of Helicobacter pylori infection: meeting the challenge of antimicrobial resistance. World J Gastroenterol 20(29):9898-9911

Papastergiou V, Georgopoulos SD, Karatapanis S (2014b) Treatment of Helicobacter pylori infection: past, present and future. World $\mathrm{J}$ Gastrointest Pathophysiol 5(4):392-399

Patel A, Shah N, Prajapati JB (2014) Clinical application of probiotics in the treatment of Helicobacter pylori infection. A brief review. $\mathrm{J}$ Microbiol Immunol Infect 47(5):429-437

Perri F, Festa V, Merla A, Quitadamo M, Clemente R, Andriulli A (2002) Amoxicillin/tetracycline combinations are inadequate as alternative therapies for Helicobacter pylori infection. Helicobacter 7:99-104

Pianoa M, Morellic L, Strozzib GP, Allesinab S, Barbab M, Deiddab F, Lorenzinib P, Ballar'ea M, Montinoa F, Orselloa M, Sartoria M, Garelloa M, Carmagnolaa S, Pagliaruloa M, Capursod L (2006) Probiotics: from research to consumer. Dig Liver Dis 38:248-255

Rodes L, Khan A, Paul A, Coussa-Charley M, Marinescu D, TomaroDuchesneau C, Shao W, Ahouli I, Prakash S (2013a) Effect of probiotics Lactobacillus and Bifidobacterium on gut-derived lipopolysaccharides and inflammatory cytokines: an in vitro study using a human colonic microbiota model. J Microbiol Biotechnol 23:518-526

Rodes L, Coussa-Charley M, Marinescu D, Paul A, Fakhoury M, Abbasi S, Khan A, Tomaro-Duchesneau C, Prakash S (2013b) Design of a novel gut bacterial adhesion model for probiotic applications. Artif Cells Nanomed Biotechnol 41(2):116-24

Ruggiero P (2014) Use of probiotics in the fight against Helicobacter pylori. World J Gastrointest Pathophysiol 5(4):384-391

Sabbi T (2011) Short review about Helicobacter pylori infection in pediatric age: epidemiological and clinical findings, diagnosis, therapy and role of probiotics. Pediatr Med Chir 33(5-6):221-226
Sachdeva A, Nagpal J (2009) Effect of fermented milk-based probiotic preparations on Helicobacter pylori eradication: a systematic review and meta-analysis of randomized-controlled trials. Eur $\mathrm{J}$ Gastroenterol Hepatol 21(1):45-53

Seck A, Burucoa C, Dia D, Mbengue M, Onambele M, Raymond J, Breurec S (2013) Primary antibiotic resistance and associated mechanisms in Helicobacter pylori isolates from Senegalese patients. Ann Clin Microbiol Antimicrob 12:3

Sgouras D, Maragkoudakis P, Petraki K, Martinez-Gonzalez B, Eriotou E, Michopoulos S, Kalantzopoulos G, Tsakalidou E, Mentis A (2004) In vitro and in vivo inhibition of Helicobacter pylori by Lactobacillus casei strain Shirota. Appl Environ Microbiol 70(1): 518-526

Taneike I, Nami A, O’Connor A (2009) Analysis of drug resistance and virulence-factor genotype of Irish Helicobacter pylori strains: is there any relationship between resistance to metronidazole and cagA status? Aliment Pharmacol Ther 30(7):784-790

Tong JL, Ran ZH, Shen J, Zhang CX, Xiao D (2007) Meta-analysis: the effect of supplementation with probiotics on eradication rates and adverse events during Helicobacter pylori eradication therapy. Aliment Pharmacol Ther 25(2):155-168

Van Doorn LJ, Scheneeberger PM, Nouhan N, Plaisier AP, Quint WG, De Boer WA (2000) Importance of Helicobacter pylori cagA andvacA status for the efficacy of antibiotic treatment. Gut 46:321-326

Vítor JM, Vale FF (2011) Alternative therapies for Helicobacter pylori: probiotics and phytomedicine. FEMS Immunol Med Microbiol 63(2):153-164

Wang F, Feng J, Chen P, Liu X, Ma M, Zhou R, Chang Y, Liu J, Li J, Zhao Q (2017) Probiotics in Helicobacter pylori eradication therapy: systematic review and network meta-analysis. Clin Res Hepatol Gastroenterol 41:466-475

Webber MA, Piddock LJ (2003) The importance of efflux pumps in bacterial antibiotic resistance. J Antimicrob Chemother 51:9-11

Wiese M, Eljaszewicz A, Andryszczyk M, Gronek S, Gackowska L, Kubiszewska I, Kaszewski W, Helmin-Basa A, Januszewska M, Motyl I, Wieczynska J, Michalkiewicz J (2012) Immunomodulatory effects of Lactobacillous plantarum and Helicobacter pylori $\mathrm{CagA}^{+}$ on the expression of selected superficial molecules on monocyte and lymphocyte and the synthesis of cytokines in whole blood culture. $\mathrm{J}$ Physiol Pharmacol 63(3):217-224

Wilhelm SM, Johnson JL, Kale-Pradhan PB (2011) Treating bugs with bugs: the role of probiotics as adjunctive therapy for Helicobacter pylori. Ann Pharmacother 45(7-8):960-966

Yang JC, Lu CW, Lin CJ (2014) Treatment of Helicobacter pylori infection: current status and future concepts. World J Gastroenterol 20(18):5283-5293

Zhang C, Zhang H, Yu L, Cao Y (2014) Helicobacter pylori dwelling on the apical surface of gastrointestinal epithelium damages the mucosal barrier through direct contact. Helicobacter 19(5):330-342

Zhengn X, Lyu L, Mei Z (2013) Lactobacillus-containing probiotic supplementation increases Helicobacter pylori eradication rate: evidence from a meta-analysis. Rev Esp Enferm Dig 105(8):445-453

Zou J, Dong J, Yu X (2009) Meta-analysis: Lactobacillus containing quadruple therapy versus standard triple first-line therapy for Helicobacter pylori eradication. Helicobacter 14(5):97-107 